\title{
AFTER SALE SERVICE DAN REPEAT PURCHASE INTENTION PADA PENGGUNA NISSAN DI FACEBOOK
}

\author{
Muhamad Rizki Ubaidilah \\ Universitas Pendidikan Indonesia \\ rizkibest@student.upi.edu \\ Agus Rahayu \\ Universitas Pendidikan Indonesia \\ agusrahayu@upi.edu \\ Rd Dian H Utama \\ Universitas Pendidikan Indonesia \\ dhutama@upi.edu
}

\begin{abstract}
ABSTRAK
Tujuan - Tujuan penelitian ini adalah untuk mengetahui pengaruh after sale service terhadap repeat purchase intention pengguna nissan di facebook.

Desain/metodologi/pendekatan - Desain penelitian ini adalah cross sectional. Penelitian ini menggunakan metode explanatory survey. Sebanyak 51 responden dipilih dengan menggunakan probability sampling berupa Cluster random sampling. Sebuah angket digunakan sebagai instrumen penelitian untuk mengumpulkan data dari responden. Teknik analisis yang digunakan adalah teknik deskriptif dengan menggunakan distribusi frekuensi dan teknik verifikatif dengan menggunakan analisis regresi linier sederhana.

Temuan - Berdasarkan hasil penelitian menggunakan analisis analisis verifikatif, didapatkan hasil bahwa After sale service memiliki pengaruh positif terhadap repeat purchase intention dengan pengaruh yang sedang.

Orisinalitas/nilai - Perbedaan penelitian ini dengan penelitian sebelumnya adalah terletak pada objek penelitian yaitu Pengguna Nissan di Facebook, dengan variabel yang diteliti yaitu After Sale Service dan Repeat Purchase Inention, serta menggunakan teori atau referensi yang berbeda dengan peneliti sebelumnya.
\end{abstract}

\section{Kata Kunci : After Sale Service, Repeat Purchase Intention.}

Jenis Artikel: Studi Kasus

\begin{abstract}
Objective - The purpose of this study is to determine the effect of after sale service to repeat purchase intention nissan users on facebook. Design / methodology / approach - The design of this study is cross sectional. This research use explanatory survey method. A total of 51 respondents were selected using probability sampling in the form of Cluster random sampling. A questionnaire was used as a research instrument to collect data from respondents. The analysis technique used is descriptive technique by using frequency distribution and verification technique by using simple linear regression analysis. Findings - Based on the results of research using analysis of verifikatif analysis, obtained the result that After sale service has a positive influence on repeat purchase intention with the influence of being. Originality / value -The difference of this research with previous research is located on the object of research that is Nissan User on Facebook,
\end{abstract}


with variables studied that is After Sale Service and Repeat Purchase Inention, and use theory or reference different from previous researcher.

Keywords: After Sale Service, Repeat Purchase Intention.

Article Types: Case Study

\section{PENDAHULUAN}

Meningkatnya persaingan antar perusahaan membuat perubahan pada perilaku konsumen, kini konsumen tidak hanya berpedoman dengan harga murah dan promosi saja tetapi pada kenyamanan, kecepatan, kebersihan dan kualitas layanan yang memuaskan, maka sebuah perusahaan harus memiliki kemampuan untuk menyediakan pelayanan yang memuasakan bagi konsumen, ketika sebuah perusahaan memberikan pelayanan yang berkualitas maka tingkat kepuasan konsumen kepada perusahaan puan akan meningkat dan kemungkinan terjadinya repeat purchase (pembelian ulang) sangat tinggi. Repeat purchase (pembelian ulang) dianggap sebagai hal yang penting dalam sebuah bisnis karena perusahaan akan mendapatkan keuntungan dengan pelanggan yang terus kembali membeli tanpa harus kesulitan mecari kembali pelanggan baru (Kim \& Joung, 2016). Salah satu hal yang paling berharga bagi perusahaan adalah pelanggan yang terus membeli produknya. Pelanggan yang terus membeli kembali sebuah produk telah memiliki sebuah ikatan yang kuat tehadap perusahaan (Tsai \& Huang, 2007), Sebuah perusahaan harus dapat mengelola repeat purchase yang dilakukan oleh pelanggan karena repeat purchase dapat menaikan penjualan perusahaan.(Chou \& Hsu, 2016). Masalah repeat purchase dapat dirasakan oleh seluruh industri salah satunya adalah industri otomotif, di dunia penelitian tentang repeat purchase intention telah banyak diteliti salah satunya penelitian yang dilakukan oleh Thanomsub, (2014) yang melakukan penelitian repeat purchase intention pada mobil Jepang di Bangkok menunjukan brand awareness, quality, dan brand loyalty berpengaruh positif terhadap repeat purchase intention, sementara di Indonesia industri otomotif telah tumbuh dan berkembang menjadi bisnis yang berpengaruh terhadap ekonomi Indonesia (Arifin \& Subagio, 2016). Terdapat banyak merek yang ada dalam industri otomotif di Indonesia mulai dari merek yang berasal dari Eropa, Amerika hingga dari Jepang. Semakin banyaknya merek yang terdapat di industri mobil membuat tingkat persaingan menjadi tinggi, dengan tingkat persaingan yang tinggi maka perusahaan akan melakukan berbagai macam strategi untuk membuat konsumen mau membeli produknya dan dapat menjadi merek yang menguasai penjualan di Indonesia. Tabel 1.1 Peringkat 10 Besar Merek Mobil dengan Penjualan Tertinggi di Indonesia, memperlihatkan peringkat penjualan mobil di Indonesia yang mana Toyota menjadi no 1 dalam penjualan di tahun 2017 di ikuti oleh Honda, Daihatsu, Suzuki, Mitsubishi, dan Datsun sementara Nissan menduduki urutan 9, meskipun berada di bawah Mitsubishi, Nissan adalah sebuah perusahaan yang besar dan masih satu grup dengan Datsun dan Infiniti.

TABEL 1. 1

PERINGKAT 10 BESAR MEREK MOBIL DENGAN PENJUALAN TERTINGGI DI INDONESIA PADA 2017

\begin{tabular}{lll}
\hline No & Merek & Jumlah \\
\hline 1 & Toyota & 371.332 Unit \\
2 & Honda & 186.859 Unit \\
3 & Daihatsu & 186.381 Unit \\
4 & Suzuki & 111.660 Unit \\
5 & Mitsubishi & 79.801 Unit \\
6 & Mitsubishi Fuso & 41.588 Unit \\
7 & Hino & 29.645 Unit \\
8 & Isuzu & 20.085 Unit \\
9 & Nissan & 14.488 Unit \\
10 & Datsun & 10.484 Unit \\
\hline
\end{tabular}




\section{Sumber: (www.gaikindo.or.id)}

Terlihat ada gambar 1.1 Nissan berada pada posisi terbawah ini berarti kepuasan pelanggan terhadap customers service Nissan buruk maka dari itu Nissan harus membenahi sector pelayanan pelangganya supaya dapat meningkatkan kepuasan pelangganya. Index pelanyanan pelanggan dapat dilihat di gambar 1.1. 2017 Indonesia customer service index (mass market) study.

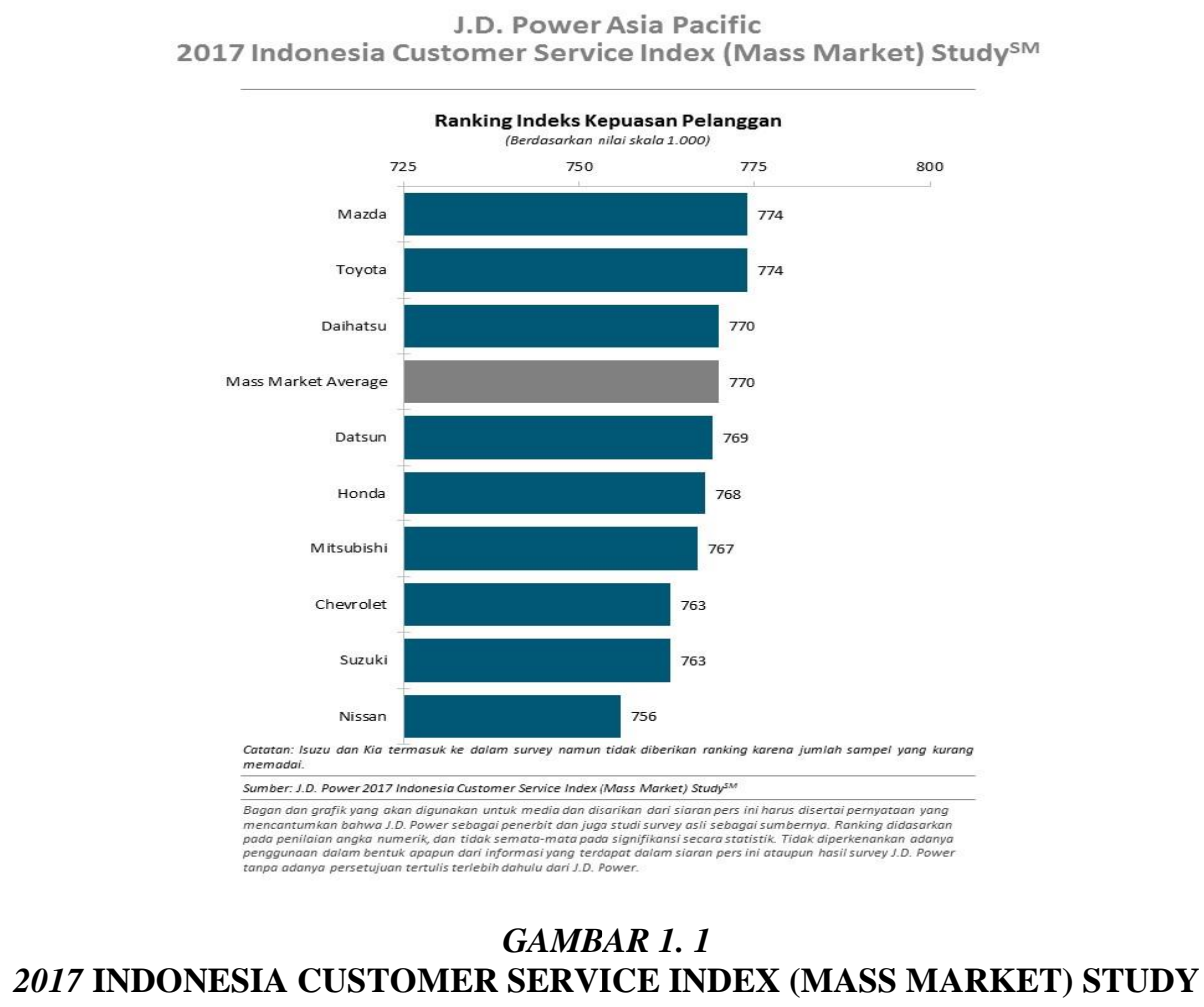

Berdasarkan penelitian yang dilakukan oleh www.jdpower.com terdapat enam faktor yang mempengaruhi kepuasan pelanggan dengan pengalaman pembelian mereka yaitu: waktu pengiriman, proses pengiriman, tenaga pemasaran, inisiasi penjualan, fasilitas dealer, dan transaksi. Semakin tinggi nilai yang didapat maka semakin tinggi kepuasan pelanggan, diantara pelanggan yang puas $35 \%$ mereka mengatakan "pasti akan" membeli merek yang sama dan $55 \%$ pelanggan mengatakan "pasti akan" merekomendasikan merek tersebut ke keluarga atau teman. dalam penelitian tersebut Nissan pada tahun 2013 menempati peringkat 9, lalu pada tahun 2014 Nissan berada peringkat yang sama yaitu peringkat 9, kemudian pada tahun 2015 Nissan mengalami kenaikan yaitu menjai peringkat 5 , namun pada tahun 2016 Nissan tetap pada peringkat 5,dan pata tahun 2017 Nissan pun masih di urutan ke 5, ini menandakan kepusasan pelanggan Nissan cenderung tetap dan sedikit mengalami kenaikan, maka ini menjadi masalah Nissan harus mencari cara agar sale satisfaction index dapat mengalami kenaikan. Berikut adalah hasil penjualan Nissan dalam kurun waktu $2010-2017$ : 
TABEL 1. 1

HASIL PENJUALAN NISSAN

TAHUN 2010-2017

\begin{tabular}{ll}
\hline Tahun & Jumlah \\
\hline 2010 & 37.542 \\
2011 & 56.137 \\
2012 & 67,143 \\
2013 & 61,112 \\
2014 & 33,798 \\
2015 & 25.108 \\
2016 & 13.153 \\
2017 & 14.488
\end{tabular}

Sumber : (www.otomotifmagz.com)(www.gaikindo.or.id)

Penurunan pembelian ini mengindikasikan menurunya repeat purchase intention pada pemiliki Nissan hal ini disebabkan anggapan masyarakat yang mengagap suku cadang Nissan mahal dan sulit di dapat (news.okezone.com) maka banyak pelanggan Nissan yang berlalih kepada merek lain seperti Toyota dan Honda yang menurut mereka harga sukucadangnya lebih murah dan lebih mudah dicari. Menurunnya repeat purchase intention pada Nissan jika dibiarkan akan menyebabkan perusahaan mengalami kerugian, karena mereka harus mencari kembali pelanggan baru dan untuk mendapatkan pelanggan baru maka perusahaan harus mengeluarkan biaya yang tidak sedikit untuk melakukan promosi agar calon pelanggan dapat mengerti dan tertarik untuk membeli produknya (Kim \& Joung, 2016).

Konsep repeat purchase intention terdapat dalam teori costomer behavior. Teori tersebut menyatakan bahwa repeat purchase intention dipengaruhi oleh after sale service (Noel, 2009). Beberapa faktor lain yang dapat mempengaruhi repeat purchase intention adalah service quality, trust, quality of product (Chou \& Hsu, 2016). after sale service merupakan faktor yang digunakan untuk mengatasi permasalahan repeat purchase intention pada penelitian ini karena after sale service merupakan suatu bagian dari proses customer behaviour untuk dapat membuat pelanggan memiliki repeat purchase intention (Noel, 2009), supaya pelanggan merasa puas maka perlu adanya quality yang baik karena permasalahan pada Nissan bayak pelanggan yang tidak merasa puas ketika mereka telah membeli produk nissan dan akan melakukan perawatan pada produk tersebut mereka kesulitan untuk mendapatkan suku cadang dan jika ada harganya masih tergolong tinggi, kesulitan dan harga sparepart yang mahal diakuin juga oleh Stephanus Ardianto sebagai Presiden Direktur NMI yang memberkan tanggapan kepada www.tribunnews.com pada tanggal 13/1/2016 yang meyatakan "Saya akui memang pandangan orang terhadap Nissan itu mobil bagus, dibawanya enak, tapi sukucadangnya susah dan mahal".

\section{KAJIAN PUSTAKA}

Pemasaran adalah suatu proses sosial dan managerial yang membuat individu dan kelompok memperoleh apa yang mereka butuhkan dan inginkan lewat penciptaan dan pertukaran timbal balik produk dan nilai dengan orang lain (Philip Kotler \& Armstrong, 2010), sementara menurut (P Kotler \& Keller, 2012) "Marketing is about identifying and meeting human and social needs", yang diartikan pemasaran adalah tentang mengidentifikasi kebutuhan hidup manusia dan social. Sementara itu menurut (Boyd, 2000) Pemasaran adalah suatu proses yang melibatkan kegiatan-kegiatan penting yang memunkinkan individu dan perusahaan mendapatkan apa yang mereka inginkan melalui pertukaran dengan pihak lain.

Menurut (Philip Kotler \& Armstrong, 2010) "Marketing mix is the set of tactical marketing tools that the firm blends to produce the response it wants in the target market", yang diartikan oleh penulis Marketing Mix adalah seperangkat alat pemasaran taktis yang dipadukan perusahaan untuk menghasilkan respon yang diinginkan sementara menurut (Angipora P, 1999) marketing mix adalah variable-variabel pemasaran terkontrol yang digabungkan perusahaan untuk menghasilkan tanggapan yang diinginkan dalam sasaran pasar.

Augmented produk merupakan sebuah produk utama yang ditambahakan berbagai layanan yang bertuajuan untuk memuaskan pelanggan.(Philip Kotler \& Armstrong, 2010) augmentd product ini terdiri dari after sale service, warranty, product support, delivery and credit. 
After sale service merupakan layanan yang diberikan perusahaan ketika pelanggan telah membeli produknya, lalu warranty adalah jaminan yang diberikan perusahaan bahwa produk yang konsumen beli bebasa dari cacat produksi. Kemudian product support adalah produk yang pelanggan beli telah di dukung oleh perusahaan baik itu dari aksesoris ataupun perlangkapan lainya. Dan delivery and credit adalah jasa yang diberikan oleh prusahaan untuk mengantarkan produk yang telah konsumen beli ke tempat yang diinginkan konsumen baik itu di antarkan ke rumah ataupun ke kantor, sementara itu credit adalah kesepakatan konsumen dan produsen bahawa produk akan di bayar dengan jangka waktu tertentu.

Menurut (Koskela, 2002) after sale service adalah suatu layanan pemeliharaan yang bertujuan untuk menjaga kelangsungan hidup suatu produk. After sale service membuat pelanggan merasa percaya bahwa produk yang mereka beli memiliki kualitas baik, mereka tidak lagi mengkhawatirkan bagaimana jika barang yang mereka beli rusak dan dimana tempat untuk mengklaim garansi sebab semua itu dapat dilakukan di jaringan after sale, maka dari itu after sale service dapat meningkatkan kepuasan pelanggan (Xu, Blankson, \& Prybutok, 2017). Pelanggan yang telah merasa percaya akan kembali membeli produk di perusahaan tersebut. Pernyataan di atas maka dapat dikatakan bahwa after sale serfice adalah layanan yang diberikan oleh perusahaan kepada pelangganya untuk menjaga kualitas dan kehandalan produknya setelah pelanggan menerima produknya.

Repeat purchase intention adalah niat membelian kembali yang dilakukan oleh pelanggan terhadap perusahaan yang sama dan bersifat berkelanjutan. (Chou \& Hsu, 2016). Repeat purchase menandakan bahwa produk yang terus dibeli oleh pelanggan adalah produk yang di sukai oleh pelanggan. (Khan, 2006). Sementara menurut (Lam, Lau, \& Cheung, 2016) repeat purchase intention merupakan tanda kepuasan pelanggan, dengan pelanggan melakukan repeat purchase mereka telah merasa puas terhadap suatu produk dengan demikian pelanggan akan kembali membeli produk tersebut. Sementara menurut (Filieri \& Lin, 2017) repeat purchase intention adalah sebuah niatan pembelian ulang yang dilakukan pembeli setelah mereka menggunakan produk yang telah mereka beli. Menurut (Noel, 2009) repeat purchase intention adalah niat membelian kembali yang dilakukan oleh pelanggan dikarenakan mereka telah merasa puas, sementara itu menurut (Chiu \& Won, 2016) repeat purchase intention adalah niat untuk membeli kembali suatu produk yang telah mebuat pelanggan puas.

\section{METODE PENELITIAN}

Penelitian ini dilakukan untuk mengetahui pengaruh after sale service terhadap repeat purchase intention pengguna nissan di facebook. Variabel adalah suatu atribut atau sifat atau nilai dari orang, objek atau kegiatan yang mempunyai variasi tertentu yang ditetapkan oleh peneliti untuk mempelajari dan kemudian di tarik kesimpulanya (sugiono, 2011). Adapun yang menjadi objek penelitian sebagai variabel terikat (Y) adalah repeat purchase intention $(\mathrm{Y})$.

Objek penelitian yang menjadi variabel bebas (X) adalah after sale service. Objek yang di jadikan responden dalam penelitian ini adalah Pengguna Nissan di Facebook.

Populasi ialah sekumpulan individuindividu dengan kualitas dan karakter yang sudah ditetapkan oleh peneliti. Ciri atau kualitas itu yang dinamakan sebagai variabel. Ia membagi populasi menjadi dua yakni populasi finit dan infinit. Suatu populasi adalah total dari semua elemen yang terbagi beberapa seperangkat karaketeristik setiap proyek riset pemasaran memiliki populasi yang didefinisikan unik untuk dijelaskan dalam istilah parameter. Tujuan dari proyek riset pemasaran yang paling adalah untuk mendapatkan informasi tentang karakteristik atau parameter dari suatu populasi (Malhotra, 2009). populasi dalam penelitian ini adalah Pengguna Nissan di Facebook sebanyak 1.906 anggota (www.facebook.com bulan Februari 2018)

Sampel adalah sebagian dari jumlah dan karakteristik yang di miliki oleh populasi (Sugiyono, 1999). Teknik pengambilan sampel yang digunakan dalam penelitian ini adalah teknik probability sampling, teknik probability sampling ini dipilih dengan mempertimbangkan kemudahan, biaya, dan waktu yang diperlukan untuk pengambilan sampel, metode yang digunakan yaitu metode cluster random sampling. Cluster random sampling merupakan cara pengambilan sampel dengan menggunakan acak dan memeprhatikan strata (tingkatan) dalam populasi tersebut (Riduwan \& Akdon, 2010), cluster random sampling digunakan untuk menentukan sampel apabila obyek yang diteliti sangat luas (Istijanto, 2016).

Data adalah fakta yang tidak sedang digunakan pada proses keputusan, biasanya dicatat dan diarsipkan tanpa maksud untuk segera diambil kembali untuk pengambilan keputusan (Margono, 2010). Sumber data adalah segala sesuatu yang dapat memberikan keterangan mengenai data, berdasarkan sumbernya data dapat di bedakan menjadi dua yaitu: data primer dan data sekunder. (Malhotra, 2010) mengungkapkan definisi data primer dan data sekunder, antara lain: 
Dalam penelitian ini yang menjadi sumber data primer adalah kuesioner yang disebarkan kepada sejumlah responden, sesuai dengan target sasaran yang dianggap mewakili seluruh populasi data penelitian, yakni survei terhadap pemilik mobil nissan di bandung. (2) Dalam penelitian ini yang menjadi sumber data sekunder yaitu artikel, jurnal, dan website, yang berkenaan dengan penelitian.

Teknik analisis data yang dilakukan adalah analisis verifikatif dengan menggunakan analisis regresi linear sederhana.

\section{HASIL PENELITIAN DAN PEMBAHASAN}

\section{Pembahasan After Sale Service}

Berdasarkan hasil pengolahan data yang dilakukan melalui penyebaran angket kepada 51 responden, didapatlah data tiap dimensi dari variabel after sale service yang akhirnya di rekapitulasi melalui perhitungan rata-rata dimensi dan perhitungan skor keseluruhan.

TABEL 4. 1

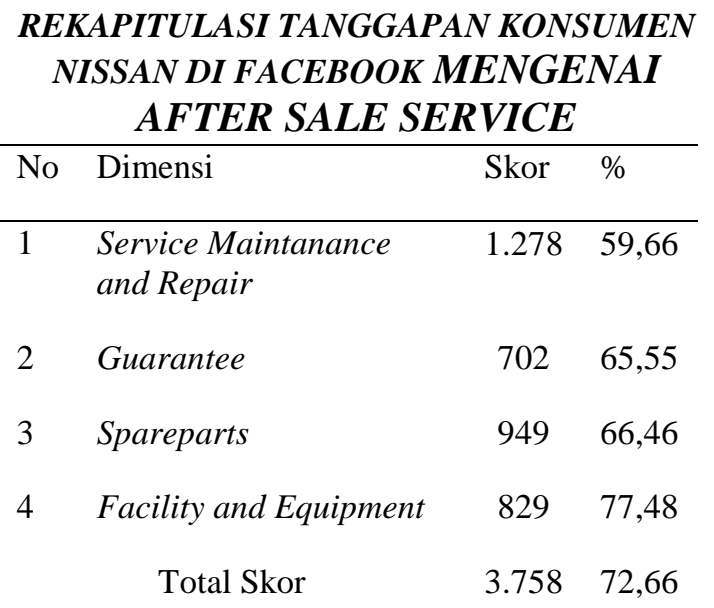

Sumber : Hasil pengolahan data 2018

Berasarkan tabel 4.8 dimensi yang mendapatkan nilai tertinggi adalah dimensi facility and equipment dengan persentase sebesar 77,48\% dan skor sebesar 829 ini menunjukan bahwa konsumen merasa fasilitas dan perlengkapan di bengkel resmi Nissan telah baik, selanjutnya indikator yang memiliki nilai terendah adalah service maintanace and repair dengan persentase sebesar 59,66\% dan dengan skor sebesar 1.278. hal ini menunjukan konsumen merasa perawatan mobil Nissan tergolong sulit dan cukup mahal.

Hasil pengolahan yang telah disajikan dapat dilihat bahwa skor total untuk aftersale service adalah 3.758 jumlah tersebut dimasukan kedalam garis kontinum sebagai berikut :

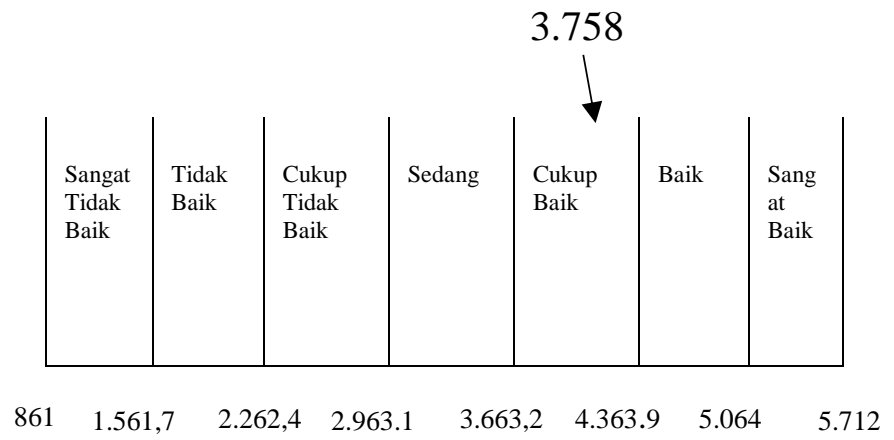

\section{GAMBAR 4. 1 \\ GARIS KONTINUM VARIABEL AFTER SALE SERVICE}

Secara ideal skor yang diharapakan untuk jawaban konsumen Nissan di facebook terhadap pertanyaan no 1-16 adalah 5.712. dari perhitungan diatas menunjukan nilai yang di dapat sebesar 3.758 dari skor ideal 5.712, degan demikian variabel after sale service berada pada kategori cukup baik.

Berdasarkan hasil rekapitulasi variabel after sale service dimensi yang mendapatkan nilai tertinggi adalah dimensi facility and equipment dengan persentase sebesar 77,48\% dan skor sebesar 829 ini menunjukan bahwa konsumen merasa fasilitas dan perlengkapan di bengkel resmi Nissan telah baik, selanjutnya indikator yang memiliki nilai terendah adalah service maintanace and repair dengan persentase sebesar $59,66 \%$ dan dengan skor sebesar 1.278. hal ini menunjukan konsumen merasa perawatan mobil Nissan tergolong sulit dan cukup mahal.

\section{Pembahasan Repeat Purchase Intention}

TABEL 4. 2

REKAPITULASI TANGGAPAN KONSUMEN NISSAN DI FACEBOOK MENGENAI REPEAT PURCHASE INTENTION

\begin{tabular}{llll}
\hline No & Dimensi & Skor & $\%$ \\
\hline 1 & Kualitas & 1.953 & 79,74 \\
2 & Merek & 1.074 & 75,21 \\
3 & Kepuasan & 1.616 & 75,44 \\
& Total Skor & 4.643 & 76,50 \\
\hline
\end{tabular}

Sumber : Hasil Pengolahan data 2018

Berdasarkan tabel 4.12 dimensi yang memiliki nilai rata-rata tertinggi adalah dimensi kualitas dengan persentase sebesar $79,74 \%$ dan dengan skor sebesar 1.953. ini menandakan kualitas dari mobil Nissan sudah baik sementara 
itu dimensi yang memiliki nilai rata-rata terendah adalah dimensi merek dengan persentase sebesar $75,21 \%$ dan dengan skor sebesar 1.074. ini menandakan citra merek Nissan belum melekat baik di masyarakat.

Hasil pengolahan data yang disajikan dapat dilihat bahwa skor total repeat purchase intention adalah 4.643 jumalah tersebut dimasukan ke dalam garis kontinum sebagai berikut :

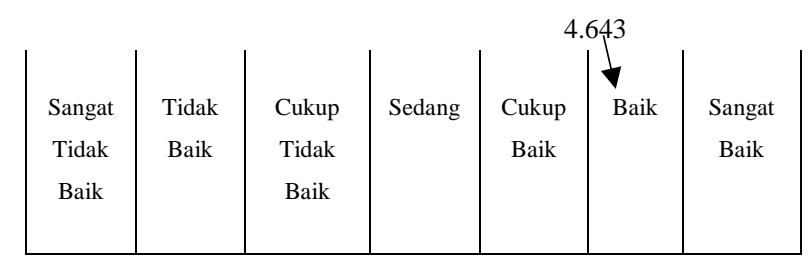

\section{GAMBAR 4. 2 \\ GARIS KONTINUM VARIABEL REPEAT PURCHASE INTENTION}

Secara ideal skor yang diharapakan untuk jawaban konsumen Nissan di facebook terhadap pertanyaan no 17-33 adalah 6.069. dari perhitungan diatas menunjukan nilai yang di dapat sebesar 4.643 dari skor ideal 6.069, degan demikian variabel repeat purchase intention berada pada kategori baik.

Berdasarkan tabel 4.12 dimensi yang memiliki nilai rata-rata tertinggi adalah dimensi kualitas dengan persentase sebesar $79,74 \%$ dan dengan skor sebesar 1.953. ini menandakan kualitas dari mobil Nissan sudah baik sementara itu dimensi yang memiliki nilai rata-rata terendah adalah dimensi merek dengan persentase sebesar $75,21 \%$ dan dengan skor sebesar 1.074. ini menandakan citra merek Nissan belum melekat baik di masyarakat.

\section{KESIMPULAN DAN REKOMENDASI}

Berdasarkan hasil penelitian yang telah dilakukan menggunakan analisis deskriptif dengan distribusi frekuensi dapat diambil kesimpulan yaitu; hasil penelitian menyatakan bahwa after sale service berada dalam kategori cukup baik dan repeat purchase intention dalam kategori tinggi.

Untuk penelitian selanjutnya, disarankan untuk menggunakan faktor-faktor lain yang mempengaruhi repeat purchase intention, memperbarui kembali teori mengenai pembelajaran kewirausahaan dan kesiapan berwirausaha serta melakukan penelitian pada field research yang lebih tepat agar hasil penelitian lebih akurat.

\section{DAFTAR PUSTAKA}

Angipora P, M. (1999). Dasar Dasar Pemasaran. jakarta: Rajawali Pers.

Arifin, A. Z., \& Subagio, R. S. (2016). Kepuasan Pelanggan Untuk Pembelian Mobil Honda, $X X(1), 63-81$.

Boyd, H. W. (2000). Manajemen Pemasaran. Jakarta: Erlangga.

Chiu, W., \& Won, D. (2016). Consumer-brand relationships in sports products and repurchase intention: An application of the investment model, 17(3), 243-259. https://doi.org/10.1108/IJSMS-08-2016-013

Chou, S. W., \& Hsu, C. S. (2016). Understanding online repurchase intention: social exchange theory and shopping habit. Information Systems and E-Business Management, 14(1), 19-45. https://doi.org/10.1007/s10257-015-0272-9

Filieri, R., \& Lin, Z. (2017). The role of aesthetic, cultural, utilitarian and branding factors in young Chinese consumers' repurchase intention of smartphone brands. Computers in Human Behavior, 67, 139-150. https://doi.org/10.1016/j.chb.2016.09.057

Istijanto. (2016). Riset Sumber Daya Manusia. Yogyakarta: PT Gramedia Pusaka Utama.

Khan, M. (2006). Consumer Behaviour And Advertising Management. New Delhi: New Age.

Kim, J., \& Joung, H.-M. (2016). Psychological underpinnings of luxury brand goods repurchase intentions: Brand-self congruity, emotional attachment, and perceived level of investment made. Journal of Global Scholars of Marketing Science, 9159(June), 1-16. https://doi.org/10.1080/21639159.2016.117 4542 
Koskela, H. (2002). Customer Satisfaction and Loyalty in After Sales Service: Modes of Care in Telecommunications Systems Delivery Customer Satisfaction and Loyalty in After Sales Service: Modes of Care in Telecommunications Systems Delivery. Management. espoo: HUT.

Kotler, P., \& Armstrong, G. (2010). Principles of Marketing. World Wide Web Internet And Web Information Systems (14E ed.). New jersey: Pearson. https://doi.org/10.2307/1250103

Kotler, P., \& Keller, K. (2012). Marketing management. (S. Wall, Ed.) (15e ed.). Kendallville: Pearson. https://doi.org/10.1080/0891176090302255 6

Lam, A. Y. C., Lau, M. M., \& Cheung, R. (2016). Modelling the Relationship among Green Perceived Value, Green Trust, Satisfaction, and Repurchase Intention of Green Products. Contemporary Management Research, 12(1), 47-60. https://doi.org/10.7903/cmr.13842

Malhotra, N. K. (2009). Marketing Research an Applied Orientation. New jersey: Pearson.

Malhotra, N. K. (2010). Marketing Research an Applied Orientation. New jersey: Pearson.

Margono. (2010). Metodologi Penelitian Pendidikan. Nursing Research (Vol. 53). Jakarta: Rineka Cipta.

Noel, H. (2009). Consumer behaviour. (D. Shaw, Ed.). Lausanne: AVA Publishing SA.

Riduwan, \& Akdon. (2010). Rumus dan Data Dalam Analisi Statistika. Bandung: Alfabeta.

Sugiyono. (1999). Metode Penelitian Pendidikan (Pendekatan Kuantitatif, Kualitatif, dan $R \& D)$. Bandung: Alfabeta.

Thanomsub, M. (2014). Factors Affecting Consumer's Purchase Intention toward Japanese Car in Bangkok.

Tsai, H. T., \& Huang, H. C. (2007). Determinants of e-repurchase intentions: An integrative model of quadruple retention drivers. Information and Management, 44(3), 231239. https://doi.org/10.1016/j.im.2006.11.006

Www.gaikindo.or.id. (2015). domestic-auto- market-by-brand-2013-2014/. Retrieved from http://www.gaikindo.or.id/domesticauto-market-by-brand-2013-2014/

Xu, L. U., Blankson, C., \& Prybutok, V. (2017). Relative Contributions of Product Quality and Service Quality in the Automobile Industry. Quality Management Journal, 24(1), 21-36.

Angipora P, M. (1999). Dasar Dasar Pemasaran. jakarta: Rajawali Pers.

Arifin, A. Z., \& Subagio, R. S. (2016). Kepuasan Pelanggan Untuk Pembelian Mobil Honda, $X X(1), 63-81$.

Boyd, H. W. (2000). Manajemen Pemasaran. Jakarta: Erlangga.

Chiu, W., \& Won, D. (2016). Consumer-brand relationships in sports products and repurchase intention: An application of the investment model, 17(3), 243-259. https://doi.org/10.1108/IJSMS-08-2016-013

Chou, S. W., \& Hsu, C. S. (2016). Understanding online repurchase intention: social exchange theory and shopping habit. Information Systems and E-Business Management, 14(1), 19-45. https://doi.org/10.1007/s10257-015-0272-9

Filieri, R., \& Lin, Z. (2017). The role of aesthetic, cultural, utilitarian and branding factors in young Chinese consumers' repurchase intention of smartphone brands. Computers in Human Behavior, 67, 139-150. https://doi.org/10.1016/j.chb.2016.09.057

Istijanto. (2016). Riset Sumber Daya Manusia. Yogyakarta: PT Gramedia Pusaka Utama.

Khan, M. (2006). Consumer Behaviour And Advertising Management. New Delhi: New Age.

Kim, J., \& Joung, H.-M. (2016). Psychological underpinnings of luxury brand goods repurchase intentions: Brand-self congruity, emotional attachment, and perceived level of investment made. Journal of Global Scholars of Marketing Science, 9159(June), $1-16$.

https://doi.org/10.1080/21639159.2016.117 4542

Koskela, H. (2002). Customer Satisfaction and Loyalty in After Sales Service: Modes of Care in Telecommunications Systems Delivery Customer Satisfaction and Loyalty 
in After Sales Service: Modes of Care in Telecommunications Systems Delivery. Management. espoo: HUT.

Kotler, P., \& Armstrong, G. (2010). Principles of Marketing. World Wide Web Internet And Web Information Systems (14E ed.). New jersey: Pearson. https://doi.org/10.2307/1250103

Kotler, P., \& Keller, K. (2012). Marketing management. (S. Wall, Ed.) (15e ed.). Kendallville:

Pearson. https://doi.org/10.1080/0891176090302255 6

Lam, A. Y. C., Lau, M. M., \& Cheung, R. (2016). Modelling the Relationship among Green Perceived Value, Green Trust, Satisfaction, and Repurchase Intention of Green Products. Contemporary Management Research, 12(1), 47-60. https://doi.org/10.7903/cmr.13842

Malhotra, N. K. (2009). Marketing Research an Applied Orientation. New jersey: Pearson.

Malhotra, N. K. (2010). Marketing Research an Applied Orientation. New jersey: Pearson.

Margono. (2010). Metodologi Penelitian Pendidikan. Nursing Research (Vol. 53). Jakarta: Rineka Cipta.

Noel, H. (2009). Consumer behaviour. (D. Shaw, Ed.). Lausanne: AVA Publishing SA.

Riduwan, \& Akdon. (2010). Rumus dan Data Dalam Analisi Statistika. Bandung: Alfabeta.

Sugiyono. (1999). Metode Penelitian Pendidikan (Pendekatan Kuantitatif, Kualitatif, dan $R \& D)$. Bandung: Alfabeta.

Thanomsub, M. (2014). Factors Affecting Consumer's Purchase Intention toward Japanese Car in Bangkok.

Tsai, H. T., \& Huang, H. C. (2007). Determinants of e-repurchase intentions: An integrative model of quadruple retention drivers. Information and Management, 44(3), 231239.

https://doi.org/10.1016/j.im.2006.11.006

Www.gaikindo.or.id. (2015). domestic-automarket-by-brand-2013-2014/. Retrieved from http://www.gaikindo.or.id/domesticauto-market-by-brand-2013-2014/
Xu, L. U., Blankson, C., \& Prybutok, V. (2017). Relative Contributions of Product Quality and Service Quality in the Automobile Industry. Quality Management Journal, 24(1), 21-36. 